\title{
POSSIBILITIES OF MANIPULATING RECOMMENDATIONS OF ELEMENTS OF THE DIGITAL TACHOGRAPHS SYSTEM AND WAYS OF PREVENTING THIS ACTION
}

\author{
Marcin Rychter \\ Motor Transport Institute \\ Diagnostics and Servicing Process Department \\ Jagiellońska Street 80, 03-301 Warsaw, Poland \\ tel.: +48224385330,fax: +48224385235 \\ e-mail:rychter@poczta.fm
}

\begin{abstract}
A tachograph which belongs to the group of ORD devices is the oldest recorder (On Board Recording Devices), and the duty of taking it was led into the USA already in 1939. The inventor of the tachograph was Max Maria von Weber, an administrative official, engineer and author. The Hasler Event Recorder was introduced in the 1920s. Regrettably, the construction of analogue tachograph, an original type of tachograph used in road transport, encouraged to numerous frauds and counterfeits of social rules for drivers In order to solve these all problems, they led with Directive of Advice No. 2135/98 from 24 September 1998 of the August of 2004 from the beginning of in the area of the European Union, new type of registering setting up in the road transport - digital tachograph. In order to make it impossible to abuse, a complex system of keys was applied cryptological and of certificates, saved in grating and devices, letting for explicit determining entitlements of users and authenticities of data, cards and devices. In spite of using, the most modern keys and securing systems, with respect to elements of the system of digital tachographs a lot of modus operandi were observed so that they registered wrong sizes. The European Union took right action in order to before to prevent, nevertheless they must be implemented into the everyday life. Those paper is include information about level of manipulation of digital tachograph and their elements, ways of manipulations of digital tachograph and future ways of counteracting manipulations.
\end{abstract}

Keywords: the tachograph card, control, digital tachograph, manipulation, technical inspection

\section{Introduction}

The tachograph, also known as recording equipment, shall be installed and used in vehicles in order to register the driving time, other periods of work or of availability, breaks from work and daily rest periods of the driver. This recording equipment is also used for recording the distance travelled by the vehicle and speed of the vehicle. Tachograph should be installed in all motor vehicles registered in European Union, which are used for the carriage of passengers (in vehicles which are constructed or permanently adapted for carrying more than nine persons including the driver and are intended to this purpose) or goods by road (where the maximum permissible mass of the vehicle, including any trailer, or semi-trailer, exceeds 3,5 tonnes).

The time caesura of the introduction of recording equipment and tachograph, is the year 1939, since when it has been stated the obligation of installation and usage of analogue tachograph in the United States of America (USA). In Europe, the tachograph is used for more than 60 years [2]. In Germany, the obligation of the installation the tachograph in vehicles was introduced in 1952 and in buses in 1953. For more than 30 years in the Member States of the European Union it has been commonly used the analogue tachographs, which have recorded data at the time of driving on cardboard sheets designed to accept and retain recorded data, commonly known as record sheets.

The multiannual application of analogue tachograph showed that the construction of these devices allows numerous abuses by the interference with their proper functioning. Increasingly, there have been cases of manipulation in analogue tachograph records. These experiences become 
a contributory factor to the quest for a device that would prevent falsification of records of the recording equipment in road transport. These requirements was to meet the digital tachograph, as a device to ensure unambiguous assessment attempts to make changes to comply with the rules relating to the working time of a driver and speed limits. To be more precise it should be pointed that digital tachograph is only the part of the completely digital tachograph system, which consists of three main elements: the motion sensor, the digital tachograph and tachograph smartcards [3].

\section{Control of digital recording devices}

Introduction of the digital tachograph in road transport had undeniably ensured:

- improving the efficiency and effectiveness of control of road haulage companies in road transport,

- the relevant standards in the field of social legislation and its harmonization in all the Member States of the European Union,

- strengthening the principles of fair competition,

- improving safety in road traffic.

The digital tachograph is a very important on-board device, used in road transport, due to control possibilities and enforcement of compliance with the legal provisions concerning the conditions of transport and social rules for drivers. Control of the road carriage (road transport and non-commercial carriage by road) it is the statutory task of the Road Transport Inspection (Article 50 of the Act of 6 September 2001 on road transport, Law Journal 2007, No 125, position 874, with changes). Additionally, police officers, Customs officers, border police inspectors and inspectors of the National Labour Inspection are also entitled to conduct the control of road haulage in area of the installation of tachographs in vehicles and the registration of the working time of drivers. The procedure of control on compliance with the provisions on periods of driving, minimum breaks and rest periods in road transport (both during roadside checks and checks in permission), as well as the required standard equipment of controllers and the list of basic elements which must be checked are determined by the regulation of Minister of Infrastructure of 2 September 2009 on the control of the carriage of goods by road (Law Journal No 145, position 1184). This regulation implements the directive 2006/22/EC of the European Parliament and of the Council of 15 March 2006 on minimum conditions for the implementation of Council Regulations (EEC) No 3820/85 and (EEC) No 3821/85 concerning social legislation relating to road transport activities and repealing Council Directive 88/599/EEC (Official Journal L 102, 11/04/2006 P. 0035 - 0044).

According to these acts, checks must be organized in such a way that:

- at least 3\% of days worked by drivers of vehicles falling within the scope of Regulation (EEC) No 3821/85 and Regulation (EC) No 561/2006 are checked,

- not less than $30 \%$ of the total number of working days shall be checked at the roadside and not less than $50 \%$ of the total number of working days shall be checked at the premises of undertakings.

When performing inspection operations regarding compliance with the rules on periods of driving, minimum breaks and rest periods the inspectors shall be equipped with the following devices able to:

- copy data from the digital tachograph installed in the vehicle and the driver card,

- read the downloaded data and its analysis or transmit the results of reading data to the office to make the analysis,

- make checks and detailed analysis of the confirmation of the digital signature attached to the data,

- analyze in order to determine the specific profile of the speed before the inspection of the registered equipment,

- check the sheets. 
Optional equipment of the inspector includes especially devices able to make photocopies and photographic documentation.

The list of basic points, which should be covered by roadside checks, was defined in annex 5 to the mentioned above regulation of the Minister of Infrastructure on the control of road carriage and it includes the following elements:

- daily driving periods, breaks and daily rest periods,

- weekly driving periods and weekly rest periods,

- sheets from previous days, which should be in the vehicle in accordance with article 15, paragraph 7 of Council Regulation (EEC) No 3821/85 or data from the same period on the driver card, in memory of the digital tachograph or print with this device,

- cases exceeded the permitted speed of the vehicle,

- instantaneous speed reached by the vehicle, saved by the digital tachograph by not more than the previous 24 hours of use of the vehicle,

- correctness of operation and use of analogue equipment and digital recording equipment or record sheets or driver card.

In addition to elements during roadside check, at the premises of undertakings should be checked:

- weekly rest periods and driving times between these rest periods,

- observance of the two-weekly limitation of driving times,

- record sheets, vehicle unit and driver card data and printouts.

Nevertheless, to the control of vehicle unit, driver card data and printouts of the digital tachograph shall apply the provisions of $\S 10$ of the regulation of the Minister of Internal Affairs and Administration of 18 July 2008 on the control of road traffic (Official Journal No 132, position 84 , with changes). Inspector should check data in the memory of the digital tachograph and driver card through the insertion of the control card to the digital tachograph, and then display and viewing them, print or download using devices for copy the information. If the driver does not have a driver card or it is unable to use due to the damage, the inspector checks the data contained in the memory of the digital tachograph on the basis of the printout. The driver is required for writing on copy of printout, made by the inspector, his name and surname, driver card or driving licence number and signature (Tab. 1).

Transport undertaking is liable for infringement dealt with obligation of installation and usage of digital tachograph, found by inspections. The penalty is imposed on the transport undertaking by administrative decision. Amount of fines for such infringement are set out in the annex no 3 to the Act on road transport. Part 6 of annex no 3 specifies 15 infringements dealt with digital tachograph and assigned them a penalty ranging from 100 to 5.000 PLN. Below is a modified extract from the annex no 3 to the Act on road transport for infringements of the provisions on the use of the digital tachograph.

Tab. 1. The catalogue of infringements dealt with digital tachograph according to Polish Act on road transport

\begin{tabular}{|c|l|c|}
\hline Position & \multicolumn{1}{|c|}{ Infringement } & $\begin{array}{c}\text { Penalty } \\
{[\text { PLN }]}\end{array}$ \\
\hline 6.1 .1 & $\begin{array}{l}\text { Performing carriage by road using vehicle that does not have the digital recording } \\
\text { equipment }\end{array}$ & 3.000 \\
\hline 6.1 .2$. & $\begin{array}{l}\text { Performing carriage by road using vehicle with a digital recording device, which does } \\
\text { not register all required elements }\end{array}$ & 2.000 \\
\hline 6.1 .3$. & $\begin{array}{l}\text { Performing carriage by road using vehicle with digital recording device, which does } \\
\text { not register, at the same time, data dealt with periods of activities of all drivers who } \\
\text { drive the vehicle in checked period }\end{array}$ & 1.000 \\
\hline 6.1 .4$. & Performing carriage by road using vehicle with digital recording equipment & 1.000 \\
\hline
\end{tabular}


Tab. 1. The catalogue of infringements dealt with digital tachograph according to Polish Act on road transport cont'd

\begin{tabular}{|c|l|c|}
\hline Position & \multicolumn{1}{|c|}{ Infringement } & $\begin{array}{c}\text { Penalty } \\
{[\text { PLN] }}\end{array}$ \\
\hline 6.1 .4$. & without the required periodical check, control check or calibration & 1.000 \\
\hline 6.1 .5$. & $\begin{array}{l}\text { Performing carriage by road vehicle with digital recording equipment, by the driver } \\
\text { without his own, valid card }\end{array}$ & 1.000 \\
\hline 6.1 .6$. & $\begin{array}{l}\text { Performing carriage by road by driver without the required print of the tachograph } \\
\text { driver card in case of damage, failure or its lack-for each missing print }\end{array}$ & 100 \\
\hline 6.2 .1$. & $\begin{array}{l}\text { The digital tachograph does not register on driver card speed of vehicle, activity of } \\
\text { driver and distance of travel }\end{array}$ & 5.000 \\
\hline 6.3 .4$. & Using the same driver card by more than one driver & 3.000 \\
\hline 6.3 .5 & Using the same driver card by more than one driver in the same time & 1.000 \\
\hline 6.3 .7$. & $\begin{array}{l}\text { Showing during check in premises of undertaking data from driver card, digital } \\
\text { tachograph or document confirming the fact of not driving the vehicle - for each day }\end{array}$ & 500 \\
\hline 6.3 .9$. & $\begin{array}{l}\text { Showing during check in premises of undertaking incomplete data on the periods of } \\
\text { driver activity - for each day }\end{array}$ & 300 \\
\hline 6.3 .11$. & Not making a copy of data from driver card - for each driver & 500 \\
\hline 6.3 .12$. & Not making a copy of data from digital tachograph - for each vehicle & 500 \\
\hline 6.3 .13 & $\begin{array}{l}\text { Not showing during check in premises of undertaking data copied from digital } \\
\text { tachograph and driver card, stored in undertaking - for each day }\end{array}$ & 300 \\
\hline 6.3 .14$. & $\begin{array}{l}\text { Interference with the data written in digital recording equipment, driver card and } \\
\text { undertaking card }\end{array}$ & 5.000 \\
\hline
\end{tabular}

It must be underlined that the driver is also liable for infringement dealt with improper usage of digital tachograph. The infringements and penalties are described in annex no 1 to the Act on road transport. For instance, for performing carriage by road using vehicle with digital recording equipment with illegal additional device influenced on incorrect function of digital tachograph the driver should be punished fine of 2000 PLN.

The ratio of issued decisions on the imposition of a penalty payment to the number of checked vehicles in the year 2010 equals $15.4 \%$ (14.4\% according to inspections of vehicles registered in Poland and $17.6 \%$ - vehicles registered abroad). In view of the comparison of the results of the checks carried out by the Road Transport Inspection from the beginning of its existence, it should be underlined the systematic decline in the number of checks with the imposition of the penalty by administrative decision in proportion to the number of controlled vehicles. The following chart shows the increase in compliance with the provisions of the transport by carriers, which covers the period from the beginning of activity of the Road Transport Inspection by 2010 (Fig. 1).

The results of the roadside checks carried out by inspectors of the Road Transport Inspection indicate a statement of more than 172000 infringements (in accordance with the annex to the Act on road transport). Approximately $70 \%$ of infringements were related to the provisions concerning driving and mandatory breaks and rest periods of drivers, over $15 \%$ of infringements were related to improper use of the recording equipment, while $10 \%$ constituted a violation of the requirements for the possession of the required licenses, certificates of accomplishment of the non-commercial, or documentation of drivers. Violations related to not paying by carriers the mandatory tolls on national roads is about $2 \%$ of the total number of infringements. The structure of infringements shows the Fig. 2.

Of the total number of approximately 65000 of infringements related to the non-observance of rules on social legislation for drivers in road transport, the most common is not allowed reduction of daily rest periods and driving time without required break. A detailed list of the number of infringements noted in respect of the working time of drivers shows the Fig. 3. 


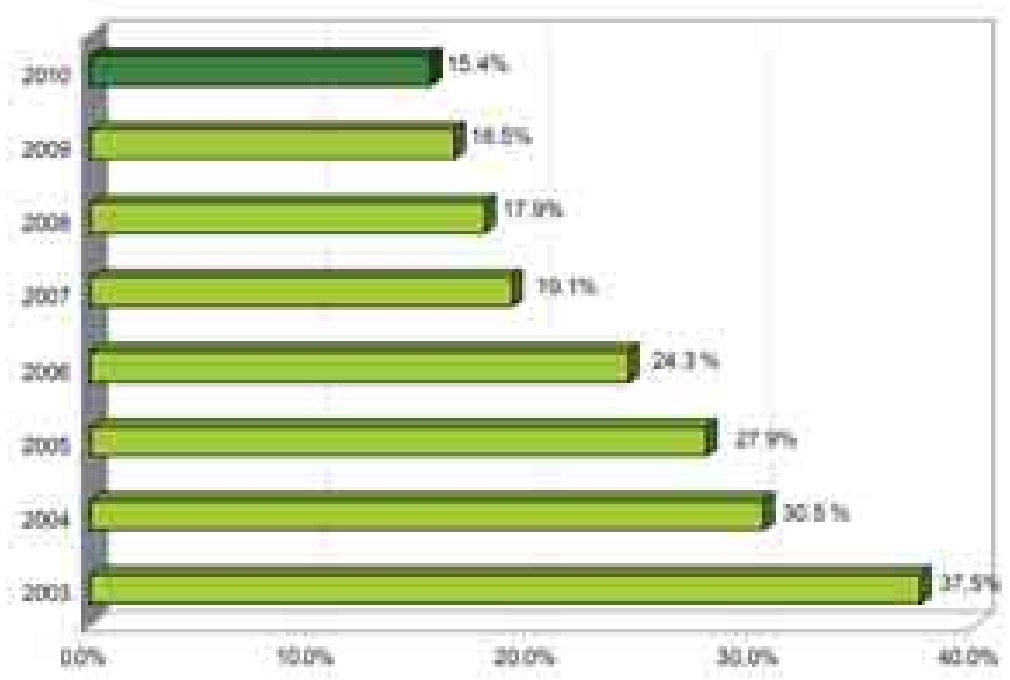

Fig. 1. The increase in compliance with the provisions of the transport

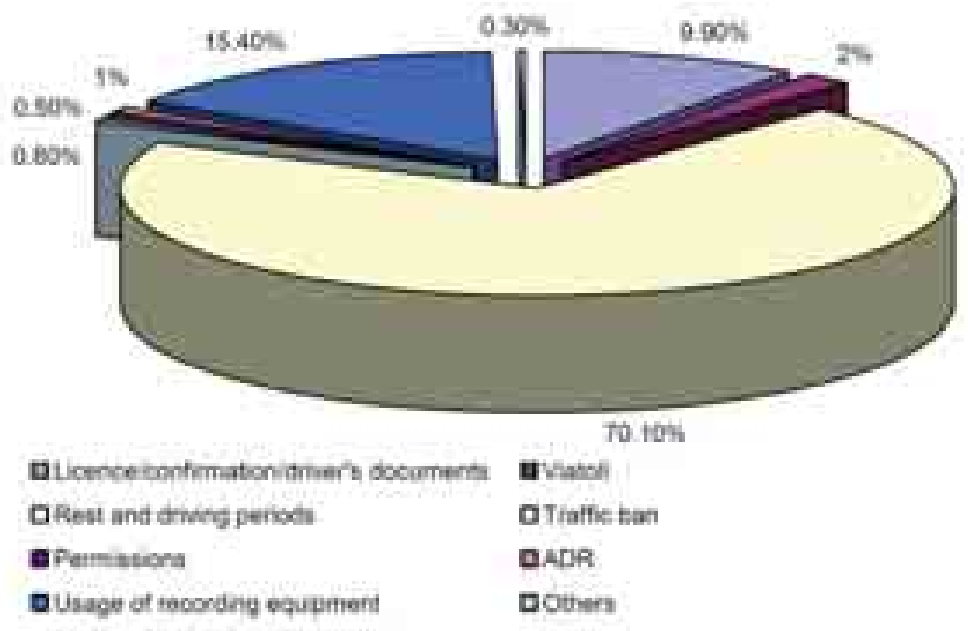

Fig. 2. The structure of infringements in road transport

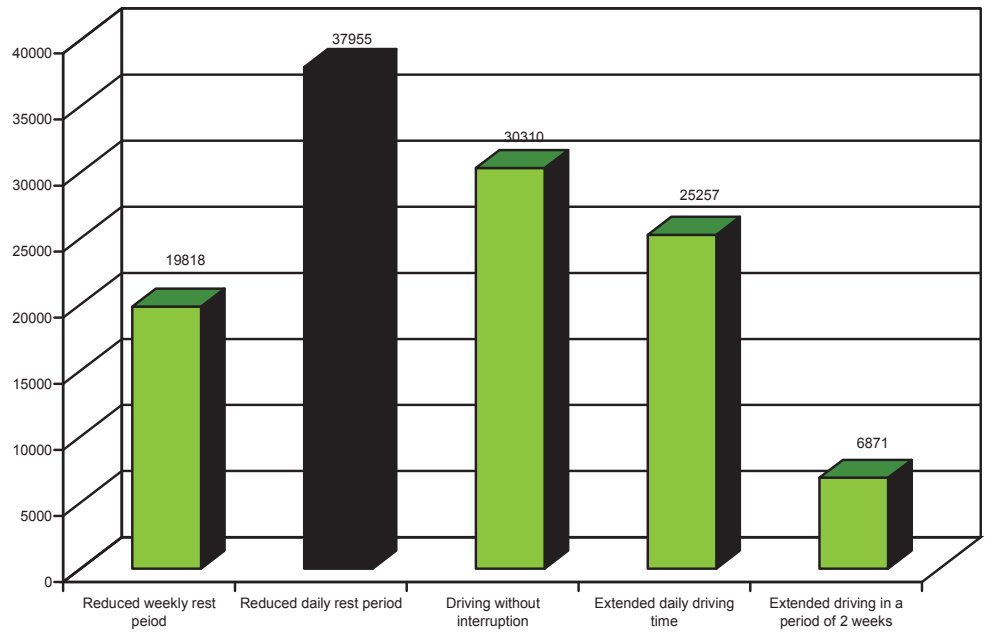

Fig.3. The number of infringements in road transport

According to infringements referred to compliance by the drivers and traders with the provisions concerning the use of recording equipment very common are cases of incorrect use of the recording equipment or the incorrect use of recorded sheets. A detailed list of the number of infringements noted in the use of the recording equipment shows the Fig. 4. 


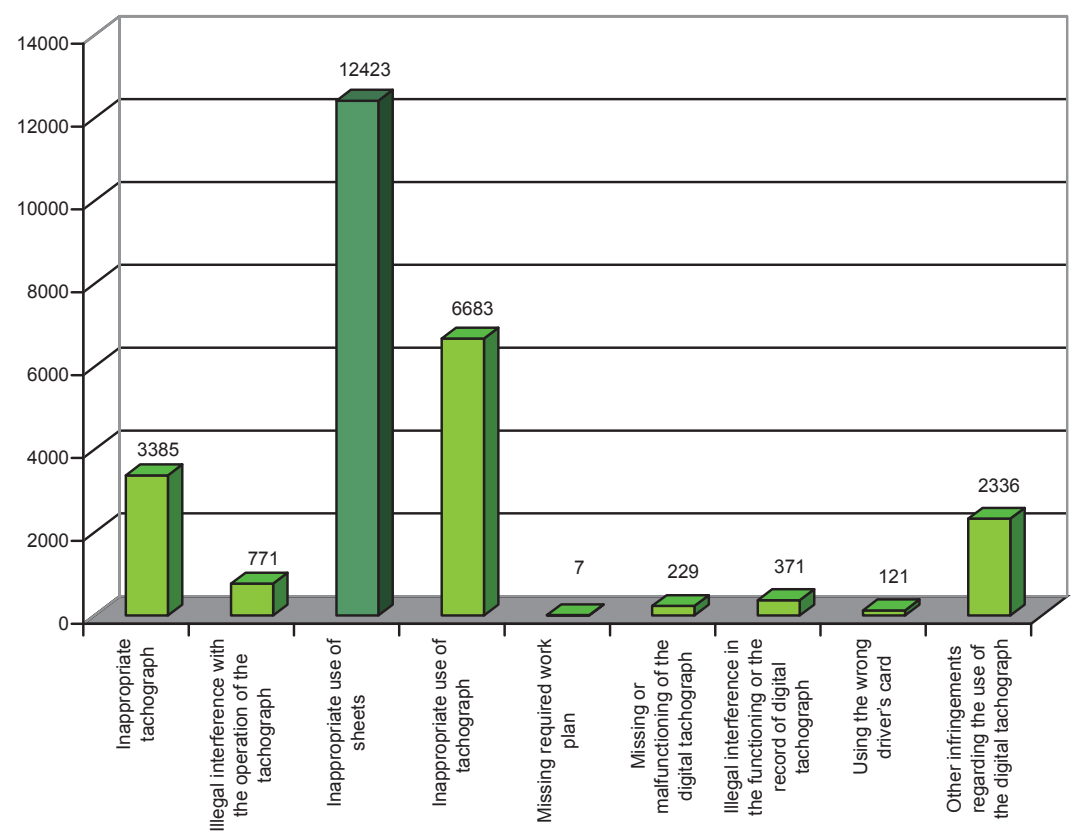

Fig. 4. The number of infringements in road transport in light of using recording equipment

Violations of the standards of the working time of drivers will also rise to the liability of the driver in the form of fines levied by the criminal mandate. This responsibility is independent of the responsibility of transport undertaking and aims to more effective compliance with the provisions concerning the standards of driving and mandatory breaks (Fig. 5).
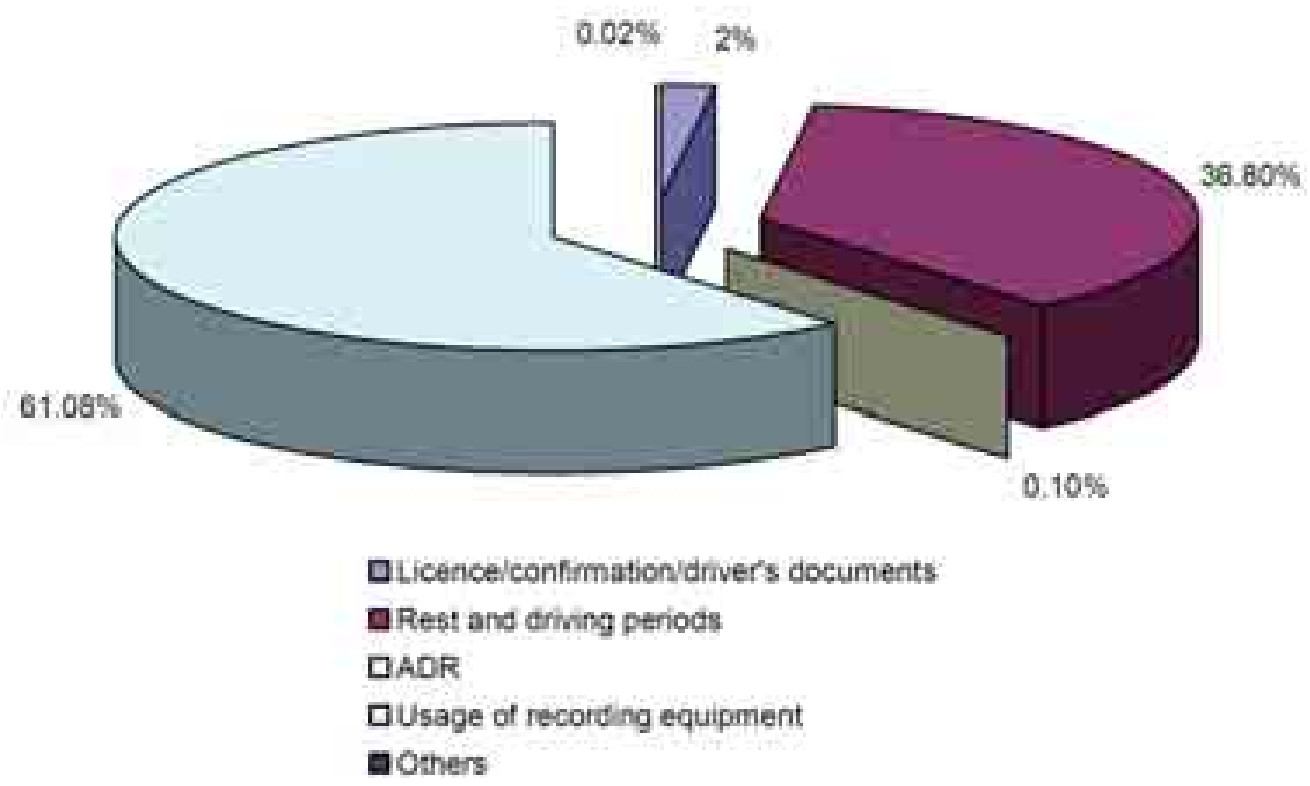

Fig. 5. The infringements number of standards of driving and mandatory breaks

As a result of the checks carried out in enterprises engaged in road transport in 2010 it was issued 2077 administrative decisions on the imposition of fines total 25000000 PLN.

As a result of checks carried out at the premises of undertakings, inspectors of the Road Transport Inspection claimed more than 243000 infringements. More than $62 \%$ of the infringements concerned the incorrect use of the recording equipment, $36 \%$ of infringements related to the non-observance by the drivers of the provisions concerning driving and mandatory breaks and rest periods, but approximately $1 \%$ were infringements referred to the violation of the 
requirements for the possession of the required licenses, certificates of accomplishment of the noncommercial, or documentation of drivers. The detailed structure of the deficiencies identified as a result of the checks on the premises of the transport undertakings shows the following chart.

\section{Guidelines for prevention of tampering with a digital recording devices during roadside checks}

One of the most important conditions of effective roadside checks is to ensure the proper training and full equipment for enforcement officers. "The digital tachograph is much like a burglar alarm in that the attacker only has to destroy confidence in it, by making it appear to be unreliable, in order to defeat it" [4] For that reason the inspectors should have a control card, and the appropriate tools to copy data from a memory on-board unit and the memory of driver card and analysis of these data or printouts, in combination with record sheets and any other documents relating to working time for drivers. Officers should also be provided with the necessary software enable quick and easy analysis of such data.

Regardless of whether the checks are carried out on the roadside, or in the premises and whether that they are related to compliance with periods of rest and driving, the roadworthiness or other aspects, officers of the control services could also be able to test the proper functioning and proper use of the equipment to detect cases of manipulation of these devices.

To achieve such tasks Member States should make the appropriate methodology and circumstances of conducting such additional checks. Therefore, the scope of these checks might be included in the national control strategy. Such methods as: method of two check points with the analysis of speed or distance, method of one check point with a detailed analysis of data or the method of one check point based on the technical inspection, increase the effectiveness of control. Ultimately, the officer could immediately order to carry out other vehicle inspection in the workshop.

The method of two checkpoints with the analysis of the actual speed or distance. Using this method of inspection, officers could measure actual speed of the vehicle at a specific point using portable or installed in some place cameras, before stopping the vehicle. Then, they could copy file containing details of speed over the last 24 hours from on-board memory unit and compare registered speed in a given point with the speed measured several kilometres before. At the checkpoint, this method requires only the comparison of two numbers after reading a file containing details of speed over the last 24 hours.

Using the method of distance in time control, it is important to remember to select the point of inspection, located in a known distance from the specific place where officers have other means (bills of collected tolls, camera records, the protocols of border inspections) that enable to specify the moment, when a vehicle stopped in this place or not. Then, officers could copy a file containing details of the speed of vehicle for the last 24 hours from memory of on-board unit, and compare these data with the average vehicle speed, based on the known distance and time needed to reach the checkpoint.

Significant differences between read data and measured or calculated speed it is possible that the manipulation of the tachograph has been made. In that situation the vehicle could be directly checked in the workshop, without the need for additional inspection in the checkpoint.

In case of data read from the memory of on-board unit, it should be underlined that data was included with a digital signature, originally generated by the digital recording equipment or driver card in order to verify the authenticity and integrity of the data.

Method of one checkpoint with a detailed analysis of the copied data. In order to confirm the suspicions as to the presence of a device to manipulate, officers should compare data on driver's activity, copied from the memory of driver card and on-board unit with any documents in the vehicle and the driver's statement. Inconsistencies between these data could form the basis for suspicion and further action. In the next stage, it should be analyzed information about events and 
faults, including attempting to breach security, interruptions in power outage, move or sensor fault, especially registered within the last 5 days.

In addition, it should be analyzed the information including technical data, with particular regard to data concerning time adjustment or calibration data. The last group of data can be predominantly useful in finding too many cases of calibration, what may indicate that they have been carried out using the workshop card, which has been stolen or lost. Control officers should check the status of identified workshop cards, including their validity in days, when they have been used for the calibration of digital recording equipment.

If control officers continue to suspect irregularities after analysis of all the data, they could perform the copying file from the memory on-board unit, containing detailed data on speed for the last 24 hours and using specialized software to check whether there were unrealistic increases or decreases the acceleration of the vehicle, and whether the profile order is consistent with other documents in the vehicle, together with the statements of the driver (the number of breaks, speed in mountainous region or in urban areas).

Presented methods of inspection with obtained evidences may justify the suspicion of the use of the device in order to manipulate the indications of the digital recording equipment.

Method of one checkpoint with a special analysis of copied data requires disposal at the checkpoint appropriate software to generate legible indications of speed changes in time, identify abnormal fluctuations in increasing speed and indicate automatically unrealistic rises or falls of the acceleration of the vehicle and any suspicious calibration of the recording equipment or any interruption of power.

Method of one checkpoint based on the technical control of seals. If it would be possible, officers should inspect the seals. If there is no seal or it is destroyed (damaged), then the driver should explain this fact. If the driver does not have a credible explanation, this may constitute the infringement and it is recommended to make directly an inspection of the vehicle in an authorised workshop.

Vehicle or data inspection in premises of undertaking. It is recommended that the competent authorities of the Member States use the possibility of controlling vehicles and on-board units, drivers with the cards drivers in the premises of transport undertaking. Data managed by the entity, must be kept for at least one year and must be available for inspection, on every request of control officers. For that reason, it could be checked any vehicle, which is located in the premises of transport undertaking. Additionally, it could be done any appropriate tests and activities, limiting to a minimum any delay, which driver could be exposed. Such controls could also cover the possibility of preparing and equipping control officers with suitable devices to enable verification of the recording equipment, in conformity with UE regulations [5] and [6].

\section{Guidelines for prevention of manipulation of digital recording equipment during technical examination}

If, after roadside check using the procedures of technical inspection, there is suspicion that it has been installed the device used to manipulate the indications of digital recording equipment, control officers would direct the vehicle to an authorised workshop. National authorities of the Member States may authorise to instruct the authorised workshop to make specific research to detect devices for manipulation.

In most cases, detailed examinations would enable the detection of erroneous pairing of the motion sensor and on-board units, which may indicate the presence of a device or equipment for manipulation. Such studies should include the control of seals and tablets of installation, testing a reference and an analysis of the copied data from the memory on-board unit.

In the case of detection of such devices, regardless whether they were actually used by the driver or not, the recording equipment should be removed from the vehicle and used as evidence. In addition, authorised workshops should be authorized to carry out the technical inspection for 
correct operation, correct recording and storage of data, and whether the calibration parameters are correctly set.

After all technical inspection and lack of detection of equipment used to manipulation of the indications, the recording equipment shall be subjected to a complete calibration and should be endorsed with a new measurement table together with the new seals, under the supervision of the regulatory authorities.

Detection of cases of the use of devices for the manipulation of the digital tachograph system and the prevention of their use is a continuous process, which requires constant engagement. With technological progress the quantity of possible interference in the system and possible risks increase. Consequently, all entities involved in ensuring the safety of the digital tachograph system, including control officers, authorized workshop, drivers and transport undertakings are very important in process of preventing the manipulation of digital tachograph.

Member States should aim to raise as much information and to develop their own strategies, threats, and also to provide a clear support in the dissemination of acquired knowledge, while a European Commission should be informed about new threats to the digital tachograph system.

\section{Permissible errors of the digital tachograph}

Periodic inspections is the combination of activities performed in order to verify that the recording equipment works properly and that its settings correspond to the parameters of the vehicle. Periodic checking should be carried out in case of:

- the repair of the recording equipment,

- the change of characteristic values of the vehicle,

- the change of value of the effective circumference of the wheel tyres,

- when the UTC (universal time coordinated ) time device differs from the UTC time by more than 20 minutes,

- the change of registration number, VRN (vehicle registration number) and RMS,

- the loss of the plaque of the digital recording equipment,

- the expiration of 24 months from the time of the last periodic inspection.

Periodic inspection of the vehicle unit shall be carried out in order to verify that the recording equipment works properly and that its settings correspond to the vehicle parameters (Tab. 7.1). It is performed in the following cases:

- to check whether it is maintained compliance with the requirements concerning the maximum tolerances on installation,

- to check whether the device has got the sign of type homologation,

- to check whether the seals on the device are not damaged,

- change the number of the vehicle unit,

- in the period of 24 months from the time of the last periodic inspection.

Tab. 2. Requirements for speed, distance and time measurement [6]

\begin{tabular}{|c|c|c|c|c|}
\hline \multicolumn{2}{|c|}{ Speed } & \multicolumn{2}{c|}{ Distance } & Time \\
\hline \multirow{2}{*}{ Measuring range } & $0-220 \mathrm{~km} / \mathrm{h}$ & $\begin{array}{c}\text { Measuring } \\
\text { range }\end{array}$ & $\begin{array}{c}0-9999999,9 \\
\mathrm{~km}\end{array}$ & \\
\cline { 1 - 3 } $\begin{array}{c}\text { Measuring range with defined } \\
\text { accuracy }\end{array}$ & $20-180 \mathrm{~km} / \mathrm{h}$ & - & - & \\
\hline
\end{tabular}


Tab. 2. Requirements for speed, distance and time measurement [6]

\begin{tabular}{|c|c|c|c|c|}
\hline \multicolumn{2}{|l|}{ Speed } & \multicolumn{2}{|c|}{ Distance } & Time \\
\hline $\begin{array}{l}\text { The accuracy of measurement before } \\
\text { installation for the factor "in" from the } \\
\text { scope of the } \\
4000-25000 \mathrm{imp} / \mathrm{km}\end{array}$ & $\pm 1 \mathrm{~km} / \mathrm{h}$ & $\begin{array}{l}\text { Accuracy } \\
\text { before } \\
\text { installation }\end{array}$ & $\pm 1 \%$ & \multirow{5}{*}{$\begin{array}{l}\text { Scope of the UTC is } \\
\text { the date and time. } \\
\text { Change the local } \\
\text { time by increments } \\
\text { of toll. } \\
\text { Accuracy of the } \\
\pm 2 \mathrm{~s} / 24 \mathrm{~h} \text {. } \\
\text { Resolution of the } \\
\pm \mathrm{s} / 24 \mathrm{~h}\end{array}$} \\
\hline $\begin{array}{l}\text { Accuracy after installation and } \\
\text { calibration }\end{array}$ & $\pm 2 \mathrm{~km} / \mathrm{h}$ & $\begin{array}{l}\text { Accuracy after } \\
\text { installation }\end{array}$ & $\pm 2 \%$ & \\
\hline $\begin{array}{l}\text { Accuracy during service, taking into } \\
\text { account changing tyres }\end{array}$ & $\pm 6 \mathrm{~km} / \mathrm{h}$ & $\begin{array}{l}\text { Accuracy } \\
\text { during service }\end{array}$ & $\pm 4 \%$ & \\
\hline Resolution & $\pm 1 \mathrm{~km} / \mathrm{h}$ & Resolution & $\pm 0.1 \mathrm{~km}$ & \\
\hline Dynamic measurement & $\begin{array}{l}2 \mathrm{~s} \text { stability after } \\
\text { acceleration or } \\
\text { braking } \\
\text { advertising spots } \\
\text { shall not exceed } \\
2 \mathrm{~m} / \mathrm{s}^{2}\end{array}$ & - & - & \\
\hline
\end{tabular}

Permissible error of speed during a period of 2 years service to $\pm 6 \mathrm{~km} / \mathrm{h}$ and is due to the accuracy of the calibration frequencies in the speed range from 20 to $180 \mathrm{~km} / \mathrm{h}$ and the characteristic coefficient of the vehicle "with" contained within the limits of from 4,000 to $25000 \mathrm{imp} / \mathrm{km}( \pm 1 \mathrm{~km} / \mathrm{h})$ speed, the error of the coefficient "w" $( \pm 1 \mathrm{~km} / \mathrm{h})$, the error on the circumference of the wheels to "l", as well as other factors. Permissible error of distance during the 2 -year service is $\pm 4 \%$ and due to the accuracy of the calibration frequencies in the speed range from 20 to $180 \mathrm{~km} / \mathrm{h}$ and the characteristic coefficient of the vehicle "with" contained in range from 4000 to $25000 \mathrm{imp} / \mathrm{km}$, the error velocities resulting from the characteristic coefficient of the vehicle "in".

The measurement of errors on installation and during use shall be carried out under conditions, which are a normal test conditions:

- vehicle without goods,

- tyres pressures in accordance with the manufacturer's instructions,

- tyres wear within the limits allowed,

- the movement of the vehicle.

\section{Summary}

Appropriate functioning of all elements of the system of digital tachographs enable to achieve the intended purpose. In general, the guarantee of security of the whole digital tachograph system is the closest cooperation of all elements of these system and the most correct functioning of each element. However, it must be underlined that in order to prevent the manipulation of the digital tachograph, first of all it is very important to provide for:

- a range of technical measures - the tachograph to be connected to a Global Navigation Satellite System device to automate the recording of the daily journey start and end location, a remote (wireless) communications function to provide a signal, only on request, to allow an enforcement officer to assess whether to stop the vehicle for further checks and a harmonised interface to allow the use of Intelligent Transport Systems (ITS) with the tachograph;

- a requirement to ensure enforcement officers are appropriately trained, establishing the methodology for initial and continuing training. 


\section{References}

[1] Blecker, T., Kersten, W., Meyer, M., High-Performance Logistics: Methods and Technologies, Berlin 2009.

[2] Rychter, M., Budowa i zastosowanie systemu tachografii cyfrowej, Warsaw 2010.

[3] Furgel, I., Lemke, K., A review of the digital tachograph system (in:) K. Lemke, Ch. Paar, M. Wolf, Embedded Security in Cars: Security Current and Future Automotive it Applications, Birkhäuser 2006.

[4] Desworte, Y., Quiquater, J. J., Gollmann, C. Meadows, Computer Security: Proceedings. Lourain-la-Neuve, $5^{\text {th }}$ European Symposium on Research in Computer Security, Belgium 1998.

[5] Commission Regulation (EU) No 1266/2009 of 16 December 2009 adapting for the tenth time to technical progress Council Regulation (EEC) No 3821/85 on recording equipment in road transport (Official Journal L 339, 22/12/2009 P. 0003 - 0023).

[6] Commission Regulation (EC) No 1360/2002 of 13 June 2002 adapting for the seventh time to technical progress Council Regulation (EEC) No 3821/85 on recording equipment in road transport (Official Journal L 207 , 05/08/2002 P. 0001 -0252). 